\title{
The effect of Pilates exercise plus CDT on heaviness, and cardiorespiratory fitness complications in women with breast cancer treatment related lymphedema:Aclinical randomized trial
}

\author{
Roghayeh Mokhtarihesari ${ }^{1}$, Roghayeh Poozesh Jadidi ${ }^{1 *}$, Zahra Shaikhi-mobarakeh ${ }^{2}$, Karim Azali Alamdari $^{3}$
}

1. Islamic Azad University, Tabriz Branch, Tabriz, Iran

2. Breast Cancer Research Center, Motamed Cancer Institute, ACECR, Tehran, Iran

3. Azarbaijan Shahid Madani University, Tabriz, Iran

Received: 1 August 2020

Accepted for publication: 17 November 2021

[EPub a head of print-24 November 2021]

Payesh: 2021; 20 (6): $731-742$

\begin{abstract}
Objective (s): Lymphedema due to breast cancer is one of the most challenging complications of breast cancer treatments. This study aimed to evaluate the effects of Pilates combined with standard complete decongestive therapy (CDT) on heaviness and cardiorespiratory fitness in breast cancer patients with lymphedema.

Methods: Thirty breast cancer patients with lymphedema were included in this randomized double-blind study. Patients were randomly and equally assigned into two groups: Pilates plus CDT group $(n=15)$ and control group (CDT only). All patients were treated with CDT for six weeks (acute phase for 3weeks and maintenance phase for 3 weeks). Heaviness and cardiorespiratory fitness were assessed by visual numerical scale and Rockport walking test respectively. Then, the changes and consequences were evaluated before and after treatment in both groups. Analysis of covariance was performed.

Results: The mean age (SD) of patients in the study was 56.3 (6.1) years. There were no significant differences between the two groups in terms of clinical and demographic variables. The results showed that the severity of heaviness was significantly reduced in both treatment groups, but there was no statistically significant difference between groups ( $\mathrm{p}=0.37$ ). Cardiopulmonary fitness (Vo2peak) increased before and after exercise intervention between control and experimental groups and a statistically significant difference was observed $(\mathrm{p}=0.038)$.

Conclusion: No adverse effect of Pilates exercise was observed among the participants in this study and the intervention improved the cardiorespiratory fitness. The results of current study suggest that Pilates can be considered as effective intervention along with CDT for treatment of lymphedema.
\end{abstract}

Key words: Pilates, breast cancer Lymphedema, Severe severity, Vo2peak

\footnotetext{
* Corresponding author: Department of Psychology, Roudehen Branch, Islamic Azad University, Roudehen, Iran

E-mail: r.hesari1353@gmail.com
} 


\section{تاثير تمرين ييلاتس همراه با درمان استاندار د احتقان زدايى تركيبى بر شدت سنكينى و آمادتى قلبى - تنفسى درزنان مبتلا به لنف ادم ناشى از درمان سرطان بِ بستان: يك كار آزمايى بالينى}

رقيه مختارى حصارى'، رقيه يوزش جديدى '، زهرا شيخى مباركه'، كريم آزالى علمدارى"

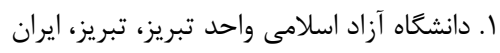

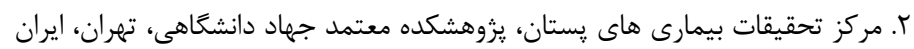

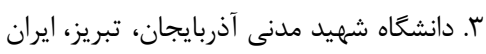

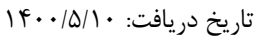

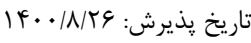

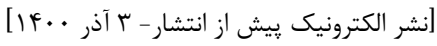

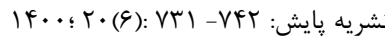

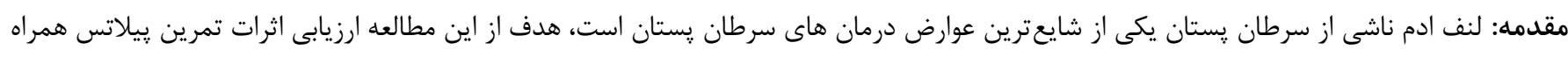

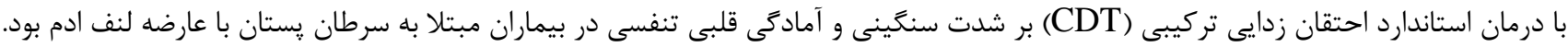

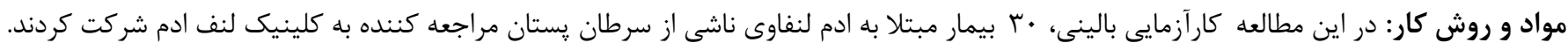

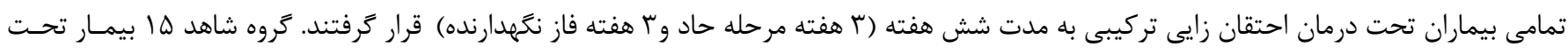

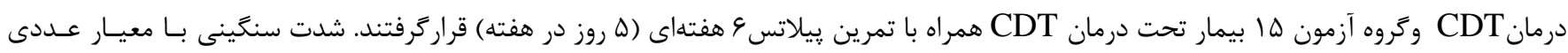

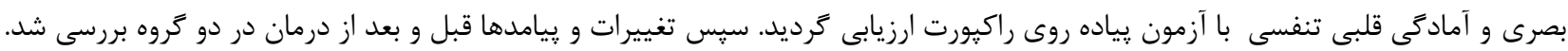

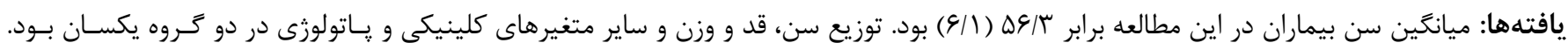

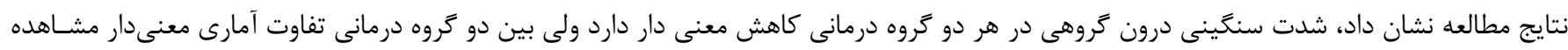

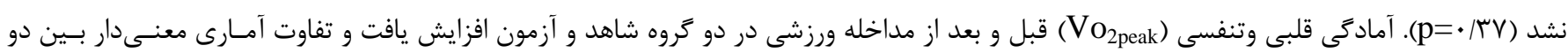

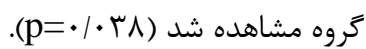

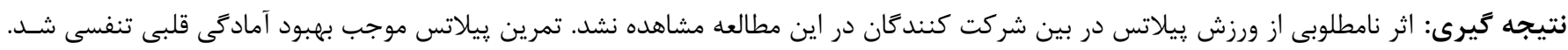

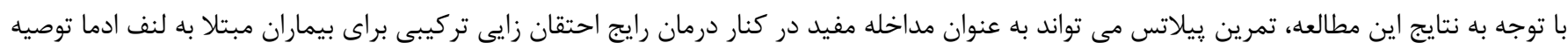

كليد وازه: بِيلاتس،سرطان بِستان لنف ادما، شدت سنكَينى، Vo2peak

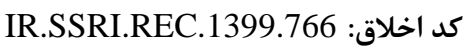
كد كار آزمايى بالينى: IRCT20200421047158N1 
تخليه لنفاوى دستى، بانــازو، لبـاس هـاى فشـرده سـازى، ورزش و

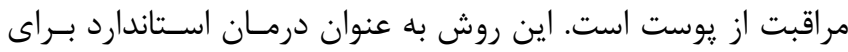

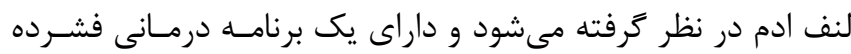
است كه از دو مرحله تشكيل شده است، مرحله اول به عنوان مرحله دانه

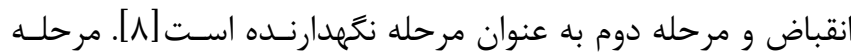

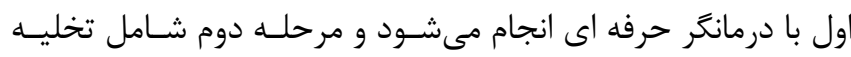

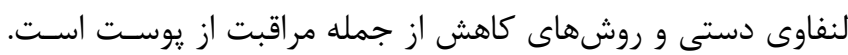

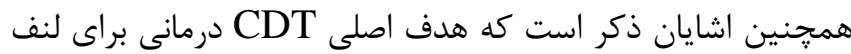

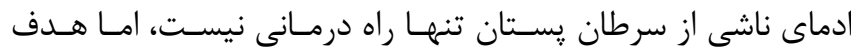

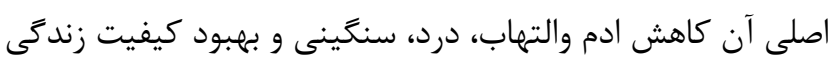

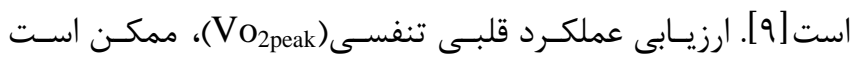

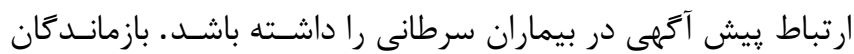

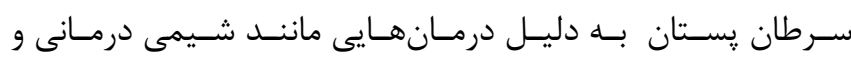

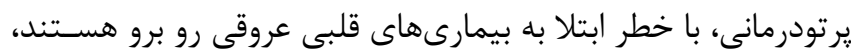

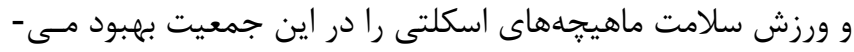

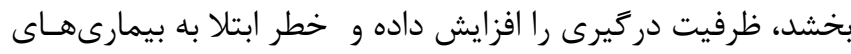

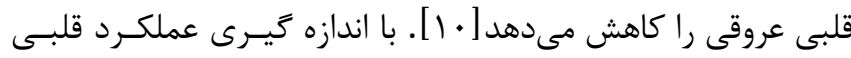

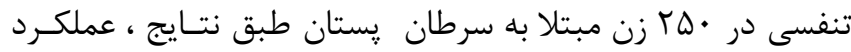

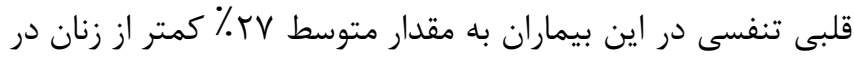

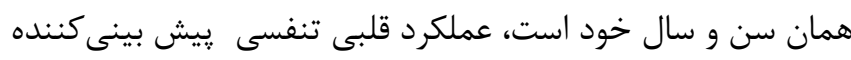

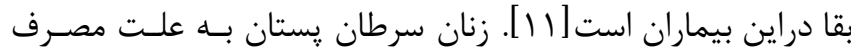

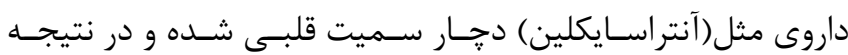

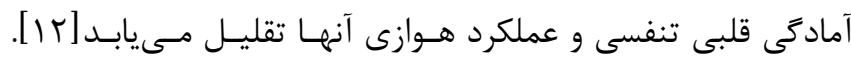
ورزش بايد به عنوان يك دارو در زنان سرطان عستان در نظر كرفته

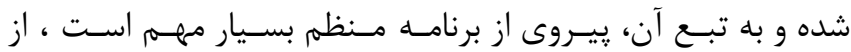

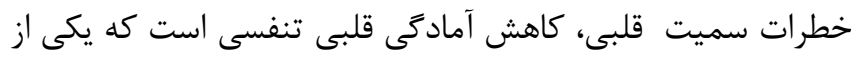

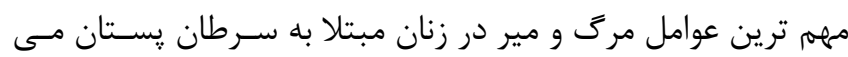

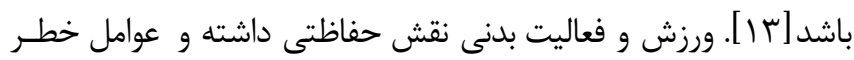

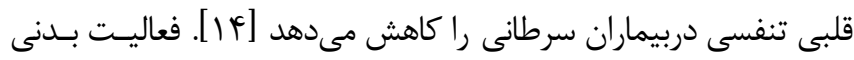

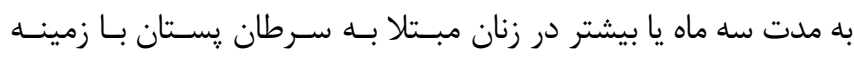

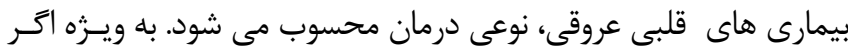

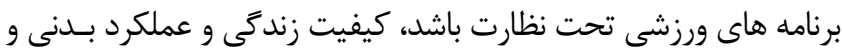

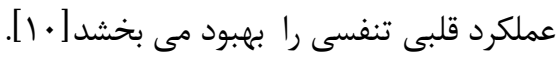

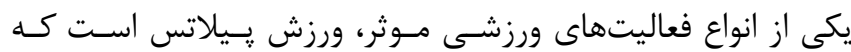

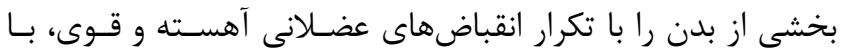

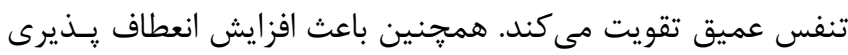

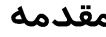

سرطان يستان شايعترين سرطان بين زنان در جهان اسـت و لنـفـ

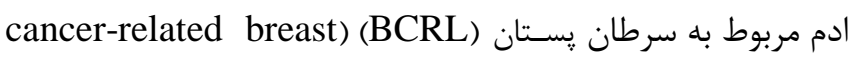

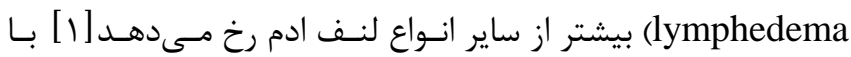
شناخت بيشتر روشهاى درمانى، درمان سرطان يستان فــوق العـاده

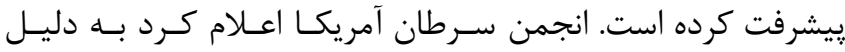

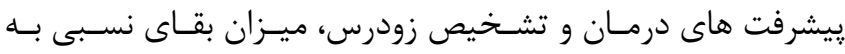

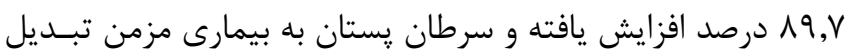

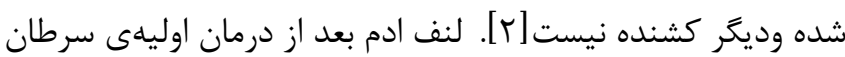

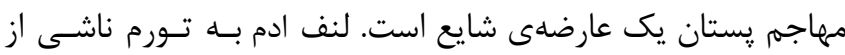

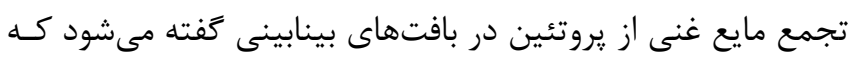

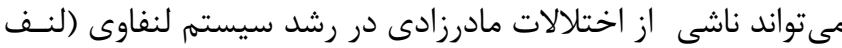

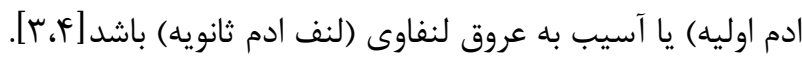

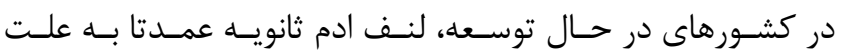
عفونتها و آلودگى ها است كه بر كانالهاى لنفاوى تأثير مسى دَـذارد.

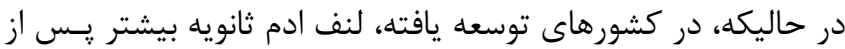

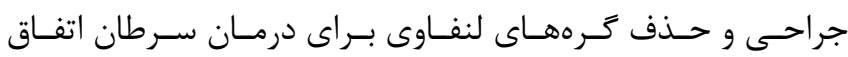

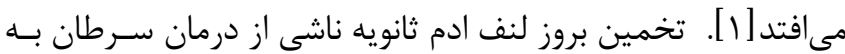

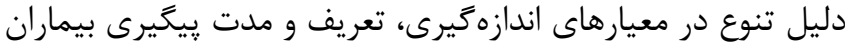

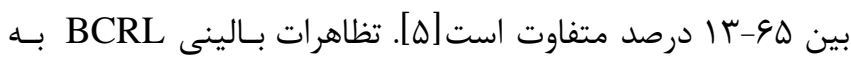

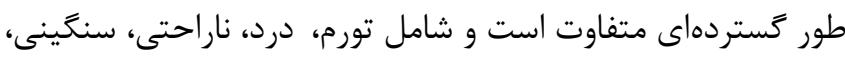

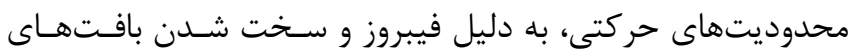

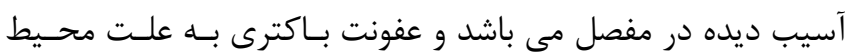

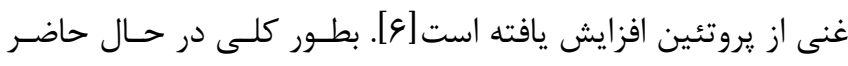

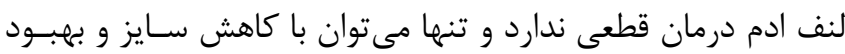
عملكرد عضو دركير و جلوكيرى از بروز عوارض، آن را كنتــرل كـرد

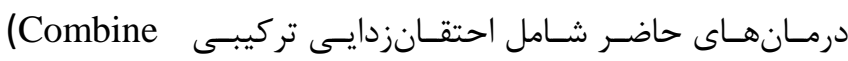
(Low Level Decongestive Therapy - CDT) Laser Therapy - LLLT) دارو و جراحسى اسـت متـداولتــــن

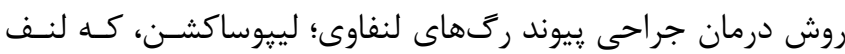

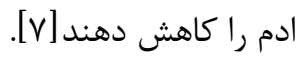

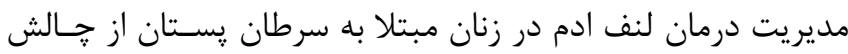

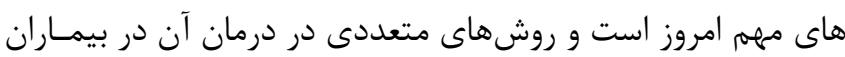

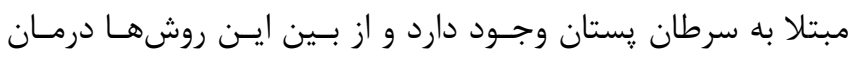

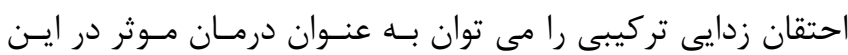

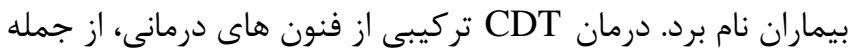




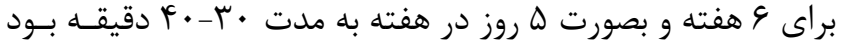

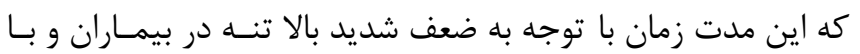

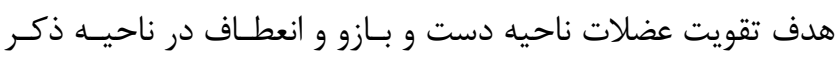
شده و همجنين افزايش آمـادگى قلبـى تنفسـى بيمـاران و كـاهش حجم ادم ودرد وسنگينى در سمت مبتلا در نظر گرفته شد.

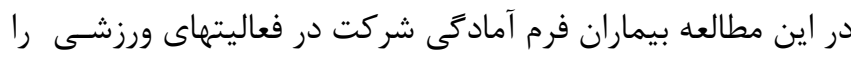
تكميل كردند و يزشك لنفولوزيست نيز شركت بيماران را در خـروه ورزش تاييد كرد. بيماران ابتدا دو جلسه آموزشى براى نحوه اجـراى يروتكل ورزش داشتند و سى دى آموزشى در اختيـار بيمـاران قـرار كرفت تا در خانه به اجراى ورزش بيردازند. مربى ورزش بـا بيمـاران در ارتباط بوده و در مراحل اجراى ورزش بر روند اجراى آن در تـك تك بيماران نظارت داشت. جهت نظارت بــر اجـراى صـحيح ورزش

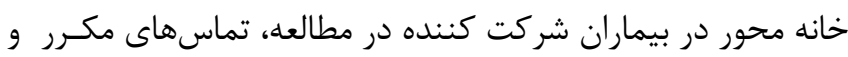

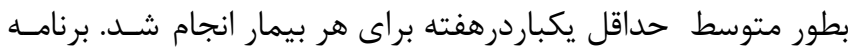
زمـانى اجــراى ورزش در بـين افـراد شـركت كنـــده متفــاوت بـود، همجنين جهت ارزيابى اجراى صحيح حركات، در صورت نياز تماس تصويرى از طريق شبكه هاى اجتماعى با بيماران انجام شد. با بررسى و مشاهده شرايط بيماران در جلسات آموزشسى و تمرينسى،

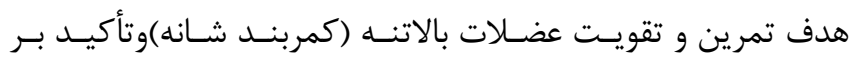
آبرسانى به بدن حين فعاليت بود. جلسات تمرينى از حالت ايسـتاده به روش صحيح ييلاتس و با اجراى دم و بازدم صـحيح شـروع شـد.

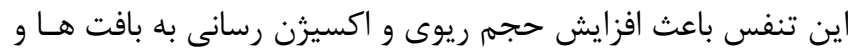

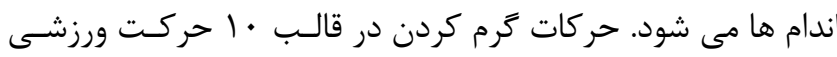

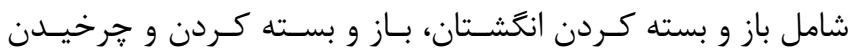

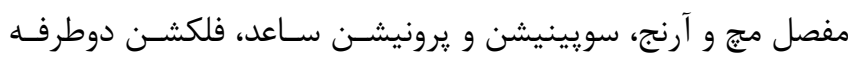

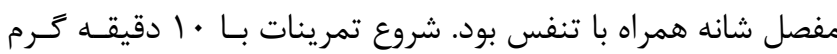

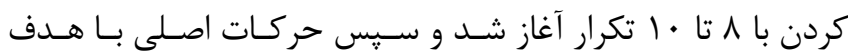
تقويت عضلات دست و سرشانه با فواصل استراحتى صـورت كرفـت. در ادامه V حركت تمرين با هوب سبك بود. اجراى اين تمرينات بـا

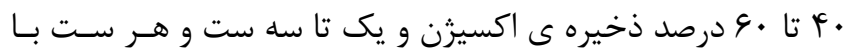
حداقل هشت و حداكثر ها تكرار و به مدت • r دقيقه انجام گرفت و در آخر تمرينات كششى و سرد كردن بدن به مدت هـ دقيقه انجـام

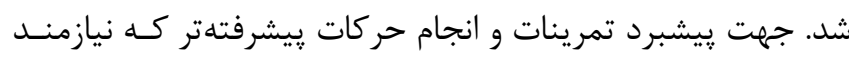
عضلات بالاتنه قوىتر بود متناسـب بــا وضـعيت بيمـاران تمرينـات بيشتر در نظر كرفته شد. شايان ذكر است حركـات رو بـهـ بـالا و بـر

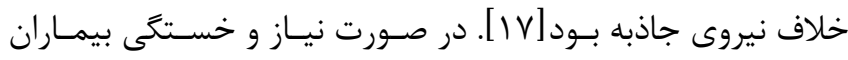

و قدرت بدن توسط عضلات مىشود و ياسجر بـدن را اصـلاح مسى-

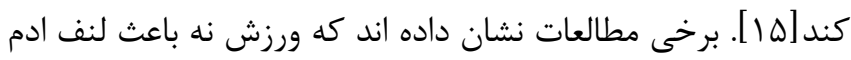

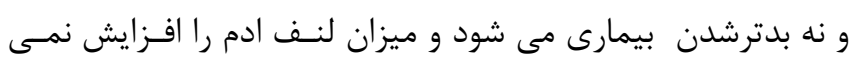

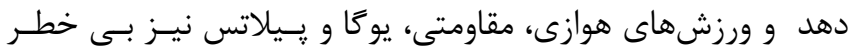

هستند [19]

به نظر مىرسد همراهـى تمـرين يـيلاتس در كنــار درمــان احتقــان

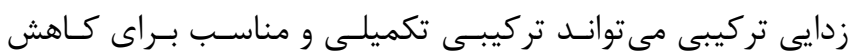

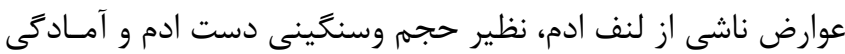

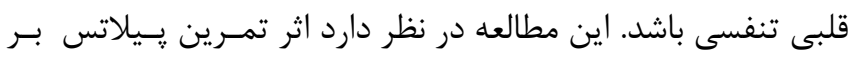
كاهش سنخينى دست ادم لنفاوى و آمادگى قلبى تنفسـى در در افـراد مبتلا به سرطان يستان با عارضه لنف ادما را بسنجد.

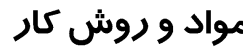

در اين كار آزمايى بالينى نيمه تجربى • ب زن يائسه با دامنه سـنى FV تا SV هدفمند انتخاب شدند. براى ورود به مطالعه، آزمودنىهـا در و مــاه كذشته هيج گونه فعاليت بدنى منظمى نداشـتـند و از آخــــين دوره قاعدگى آنها دست كم يك سال گذشته بود. يیش از اجراى يزوهش

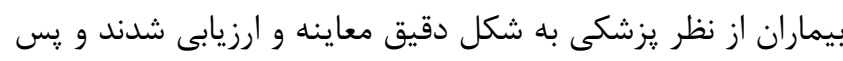

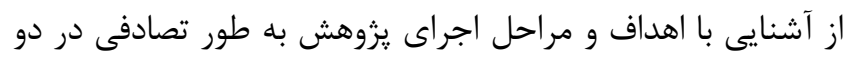

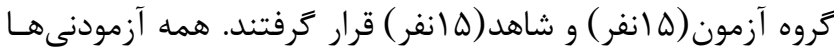
قبل از شركت در يروهش، فرم رضايت نامه را تكميل كردند. و فـرم آمـادگى شـركت در فعاليـت هــاى ورزشـى بيمـاران) (PAR-Q) توســط (Physical Activity Readiness-Questionnaire) يزشك تاييد شد. در مطالعه حاضر زنـان مبــتلا بــه لنـف ادم ثانويـهـ اندام فوقانى بر اساس معيارهاى ورود و خروج مطالعه، شركت كردند كه توسط يزشك لنفوتراييست انتخاب شدند. معيار ورود به مطالعـهـ حاضر شامل داشتن لنف ادم يكطرفه اندام فوقـانى بـهـ دنبـال عمـل

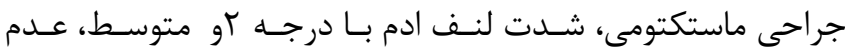

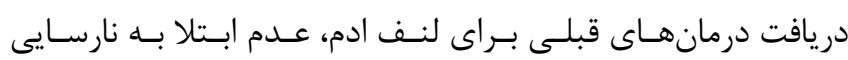

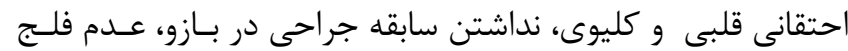
شل در بازو و نداشتن هر گَونه آسيب عصبى اندام فوقـانى، نداشـتن

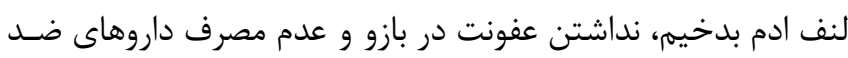

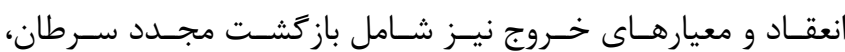
وجودعفونت در بازو، قرمزى، خارش شـديد يوسـت در اثـر بانـداز و

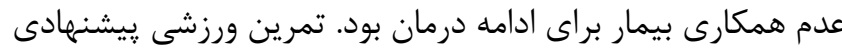


كه شامل اY جلسه درمانى هست. تا به امروز روش درمـان احتقـان

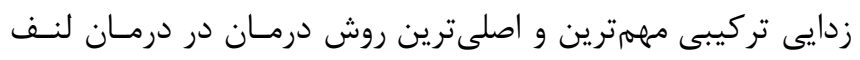

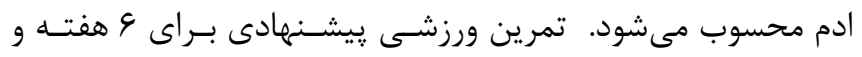

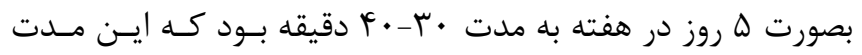

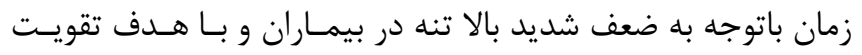

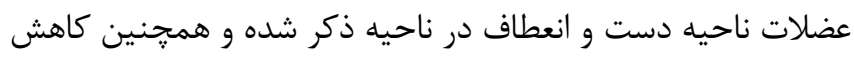

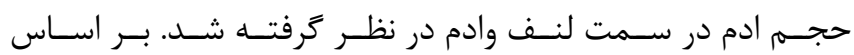
توصيه هاى كالج آمريكايى يزشكى ورزشى در مـورد ورزش بيمـاران

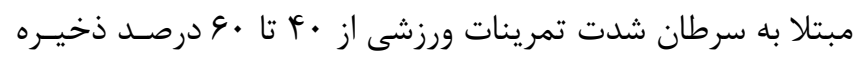

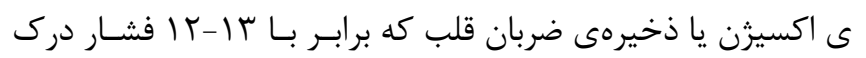
شده است، متغير است كه اين افزايش بايد به صورت تدريجى باشدي

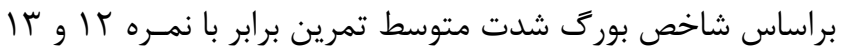

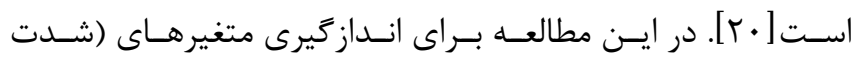

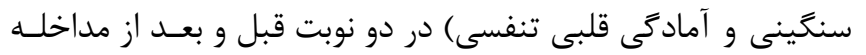

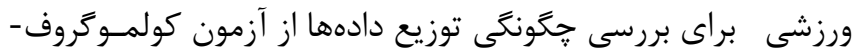

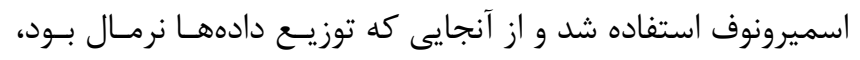

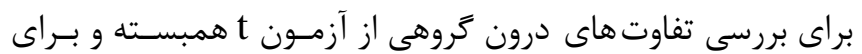

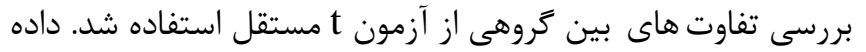

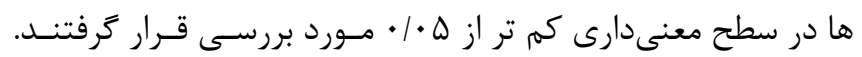

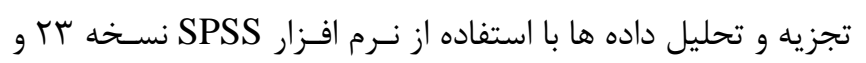

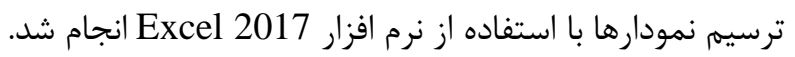

\section{يافتهها}

ميانخين سن بيماران شركت كننده در مطالعه برابر (1/

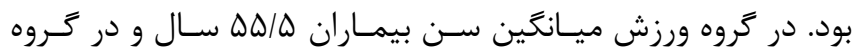

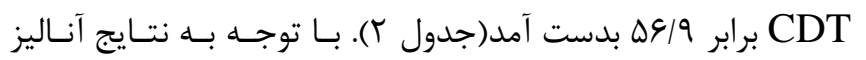

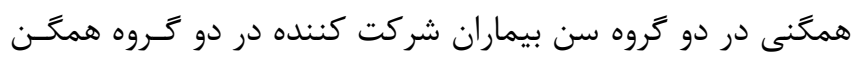

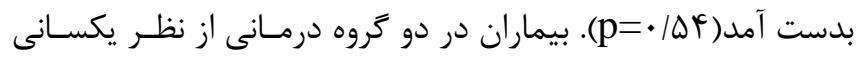
متغيرهاى داشتن فيبرز و مصرف دارو نيز تفاوت معنى دار نداشـتند.

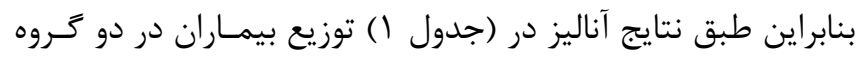

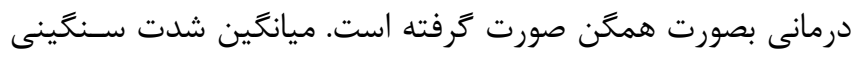

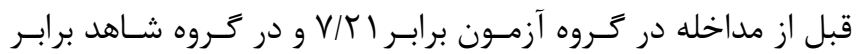

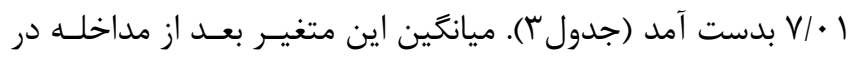

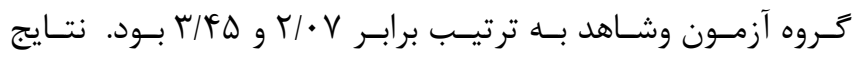

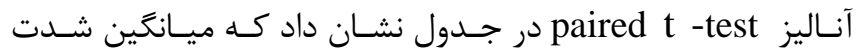

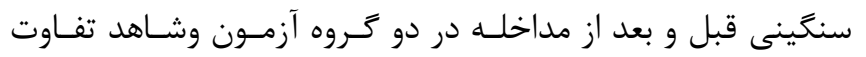

استفاده از صندلى بلامانع بود. در طول تمرين به بيماران توصيه شد

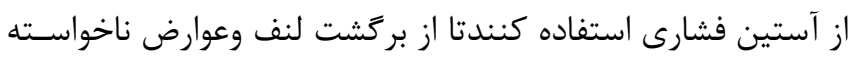
جلو زيرى شود.

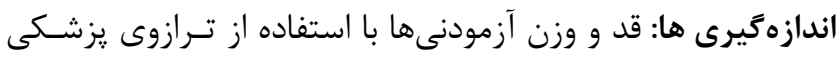

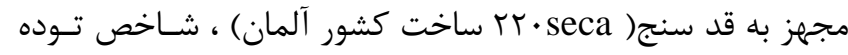

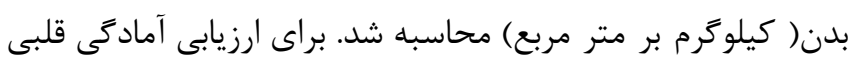

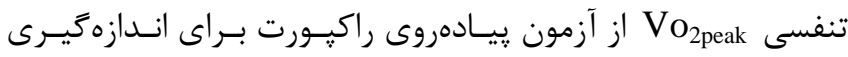

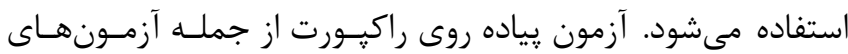

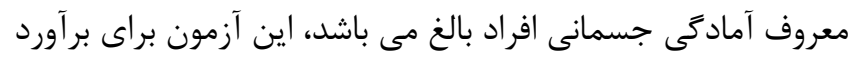

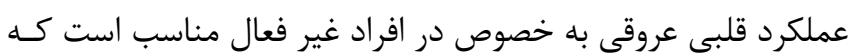

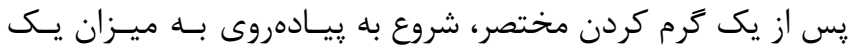

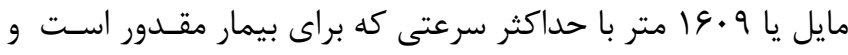

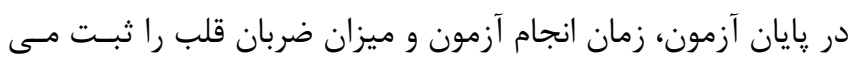

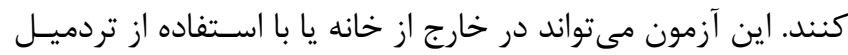

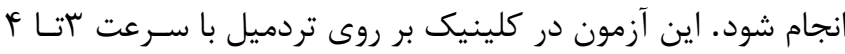

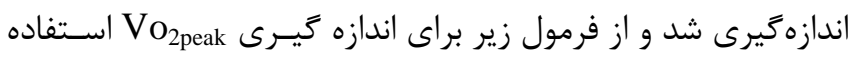
كرديد.

$\mathrm{Vo}_{2 \text { peak }}=139 / 68-(0 / 388 \times$ Age $)-[0 / 077 \times$ weight $($ pound $)]-$ [3/265× time (minute) ] -[0/156hart ratex(min)]

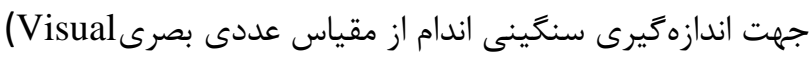
استفاده كرديد. اين مقياس يك قـاره خطط . Analog Scale)

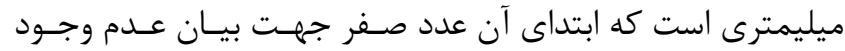

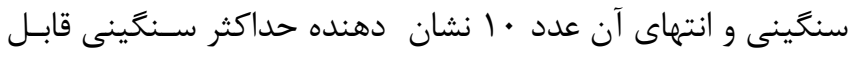
تصور براى بيمار علامت كذارى شده است. يـس از ارائـهـ توضسيحات

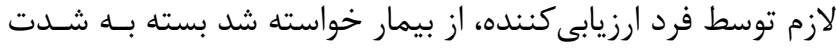
سنكينى در اندام فوقانى خود در حالت ايستاده كه دسـتها در كنـار

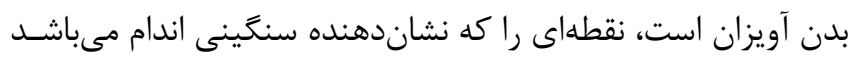

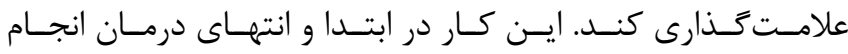

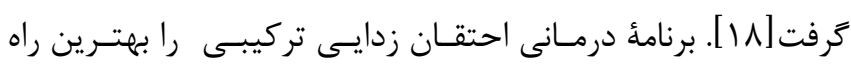

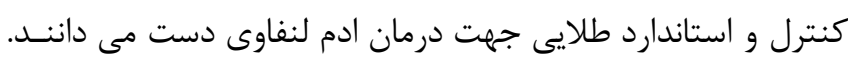

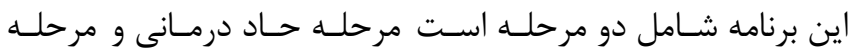

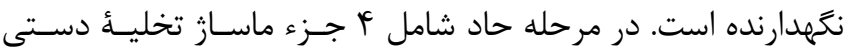

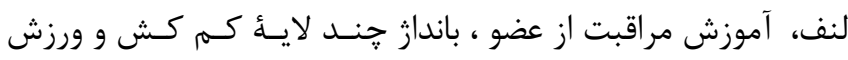

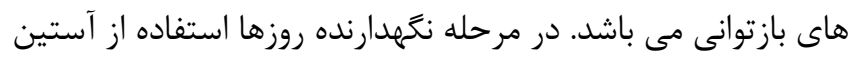

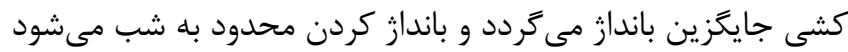

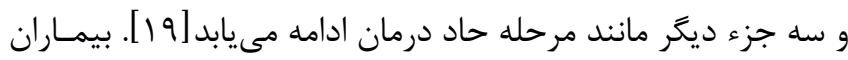

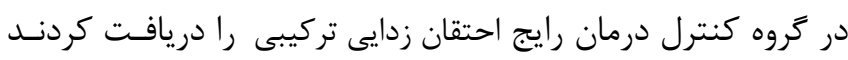


نشريه يزوهشكده علوم بهداشتى جهاددانشخاهى

آمادگى قلبى وتنفسى قبل و بعد از مداخله در هر دو گَروه درمـانى

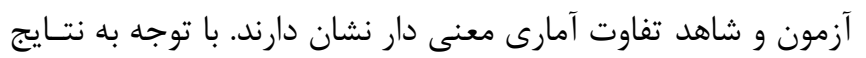

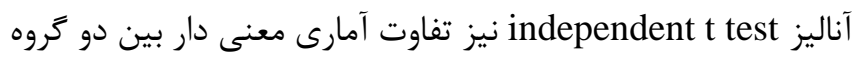
درمانى آزمون و شاهد مشاهد شد(
آمارى معنى دارى نشان داد(ه •|•>م). بـا توجـهـه بـه نتـايج آنـاليز independent t test

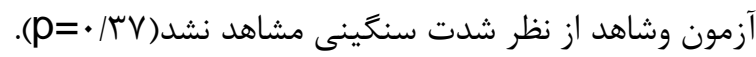

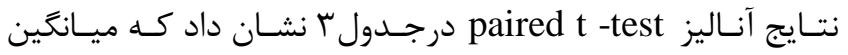

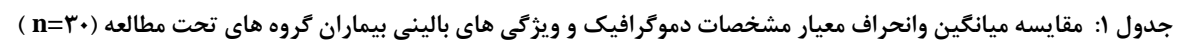

\begin{tabular}{|c|c|c|c|c|c|}
\hline \multirow[t]{2}{*}{ P-value } & \multicolumn{2}{|c|}{ كروه شاهد (D=10) } & \multicolumn{2}{|c|}{ كروه آزمون (D=آ n ) } & \\
\hline & درصد & تعداد & درصد & تعداد & \\
\hline \multirow[t]{3}{*}{$.19 \Lambda$} & & & & & نوع جراحى \\
\hline & $(\Lambda \& / \vee)$ & ir & $(\wedge \& / \vee)$ & 14 & برداشت كامل يستان \\
\hline & $(1 \Gamma / T)$ & r & $(1 r / \Gamma)$ & r & حفظ هستان \\
\hline \multirow[t]{3}{*}{.194} & & & & & يرتو درمانى \\
\hline & $(\Lambda \cdot)$ & ir & $(\Lambda \& / V)$ & ir & دارد \\
\hline & $(Y \cdot)$ & r & $(1 \% / \Gamma)$ & r & 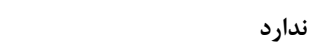 \\
\hline \multirow[t]{3}{*}{ זس/. } & & & & & شيمى درمانى \\
\hline & $(1 \cdots)$ & 10 & $(9 T / V)$ & If & دارد \\
\hline & . & . & $(V / \Gamma)$ & 1 & 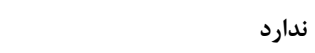 \\
\hline \multirow[t]{5}{*}{$\cdot /$ rq६ } & & & & & مرحله بيمارى \\
\hline & $(\varepsilon / V)$ & 1 & $(g / V)$ & 1 & \\
\hline & $(\Gamma / \Gamma)$ & $\Delta$ & $(\boldsymbol{F} \cdot)$ & 4 & Stage I \\
\hline & $(\varphi \cdot)$ & 9 & $(\Delta / \Gamma)$ & $\wedge$ & Stage IIA \\
\hline & & & & & Stage IIB \\
\hline \multirow[t]{3}{*}{$\cdot / 1 \Delta F$} & & & & & جراحى يستان \\
\hline & $(\wedge \varepsilon / \vee)$ & ir & $(\wedge \cdot)$ & ir & راديكال ماستكتومى تعديل شده \\
\hline & $(1 T / r)$ & r & $(T \cdot)$ & $r$ & جراحى حفظ يستان \\
\hline \multirow[t]{3}{*}{.109} & & & & & داشتن فيبروز \\
\hline & $(T \cdot)$ & r & $(1 \% / \Gamma)$ & r & 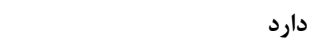 \\
\hline & $(\Lambda \cdot)$ & ir & $(\Lambda \& / V)$ & ir & 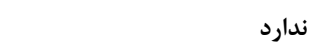 \\
\hline \multirow[t]{3}{*}{$\cdot / f$} & & & & & تحت درمان با دارو \\
\hline & $(\varphi \cdot)$ & 9 & $(\Delta T / \Gamma)$ & $\wedge$ & بله \\
\hline & $(\boldsymbol{c} \cdot)$ & 9 & $(\varphi q / V)$ & v & خير \\
\hline
\end{tabular}

جدول r: مقايسه ميانگين وانحراف معيار مشخصات دموكرافيك و بالينى كروه هاى تحت مطالعه (•rn )

\begin{tabular}{|c|c|c|c|}
\hline P-value & 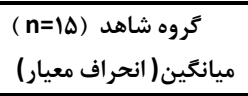 & 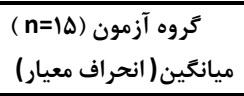 & \\
\hline$\cdot / \Delta F$ & $\Delta \Delta / \Delta(\Delta / \cdot \mathcal{C})$ & $\Delta \varepsilon / q(V / l)$ & سن (سال) \\
\hline$\cdot / 4 \wedge$ & $r \cdot / l f(f / f v)$ & rq/As $(F / r /)$ & شاخص توده بدنى( كيلوكرم بر متر مربع) \\
\hline$\cdot / 4 V$ & $19 \cdot / \Lambda T(\mid r / 9)$ & IDN/FT $(I T / S)$ & قد سانتى متر ) \\
\hline$\cdot / r$ & VV/৭८ ( N/r) & $V F / q \Lambda(\Lambda / F)$ & 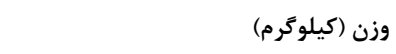 \\
\hline$\cdot 109$ & $1 \cdot / V \&(\mid \mathrm{F} / \cdot \Lambda)$ & 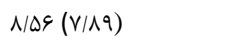 & طول مدت ادم(ماه) \\
\hline$\cdot / 49$ & $F r / F(T F / Q q)$ & $r T / Q T(r \Delta / \& r)$ & فاصله جراحى تا بروز لنف ادم(ماه) \\
\hline
\end{tabular}


سال بيستم، شماره ششم، آذر ـدى ...

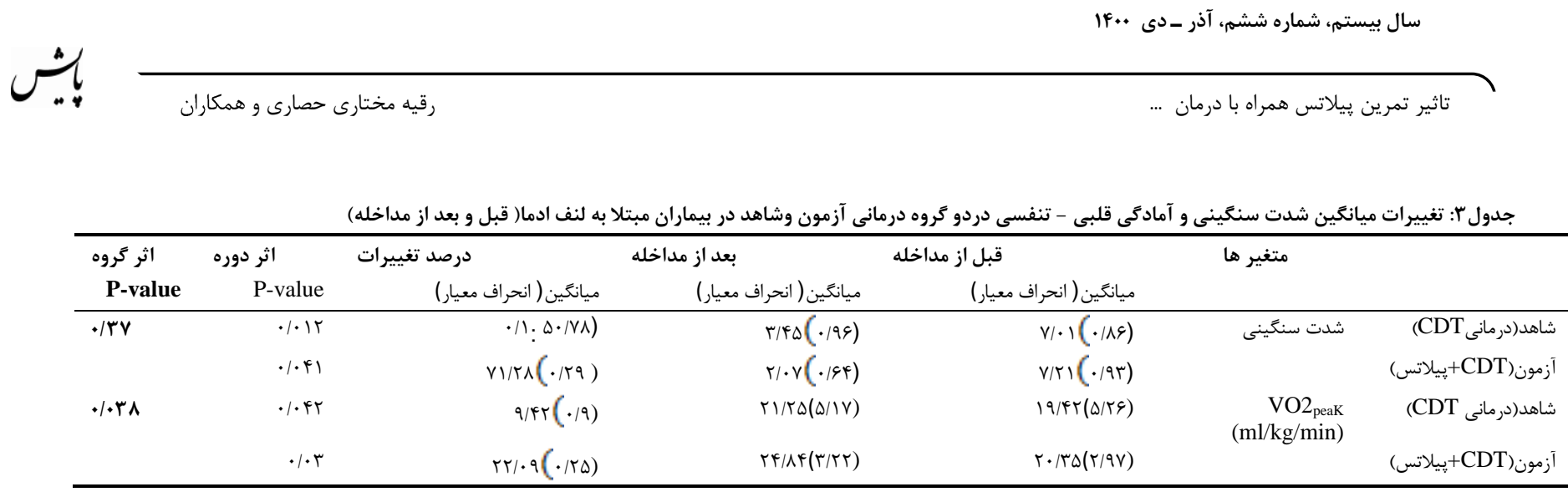

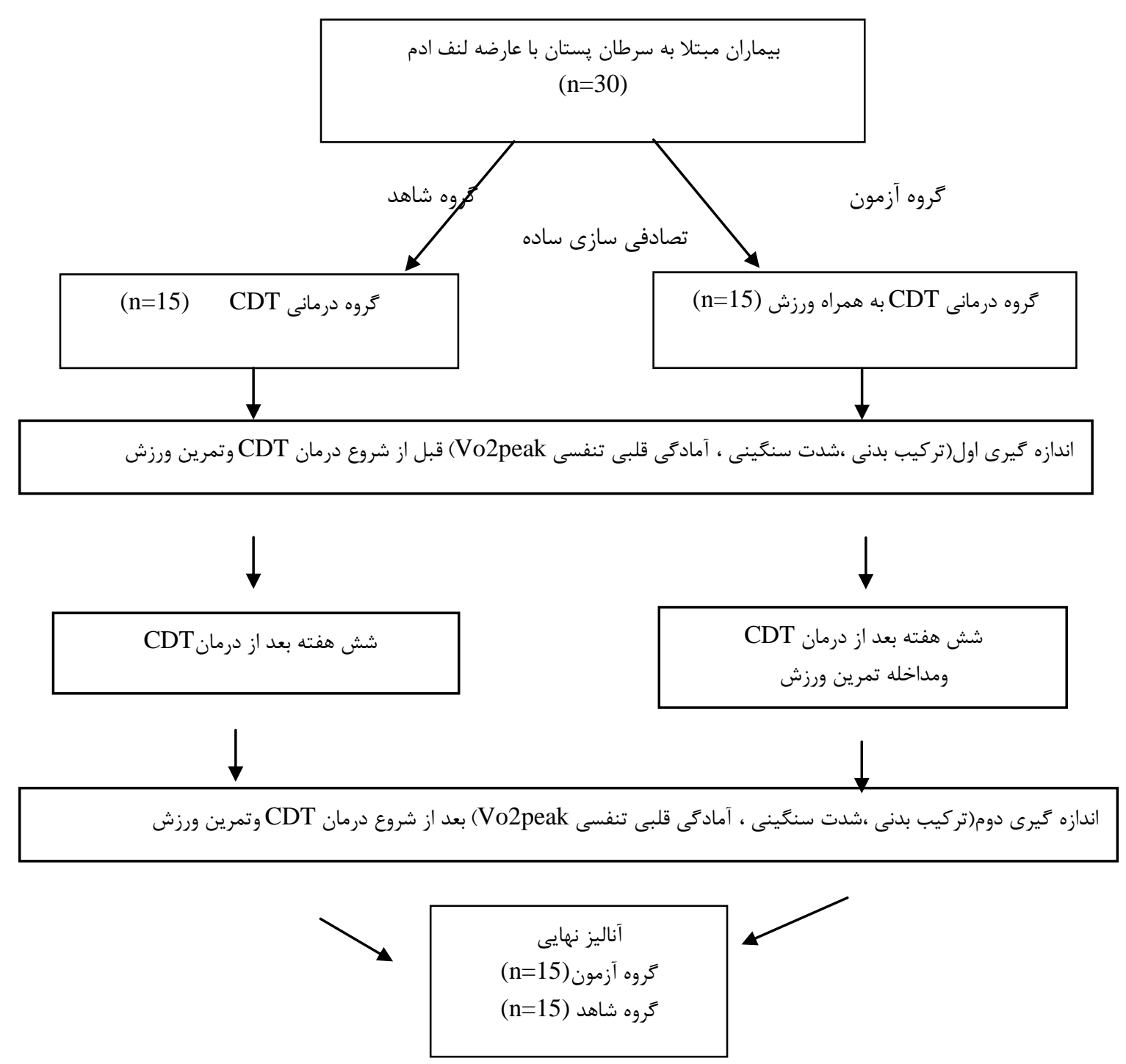

نمودار ا: يرو تكل اجراى فر آيند كارآزمايى بالينى با مداخله ورزش و درمان احتقان زدايى تركيبى براى اندازكيرى متغيرهاى (شدت سنكينى و آمادكى قلبى تنفسى) در بيماران مبتلا به سرطان يستان با عارضه لنف ادم زدائ 


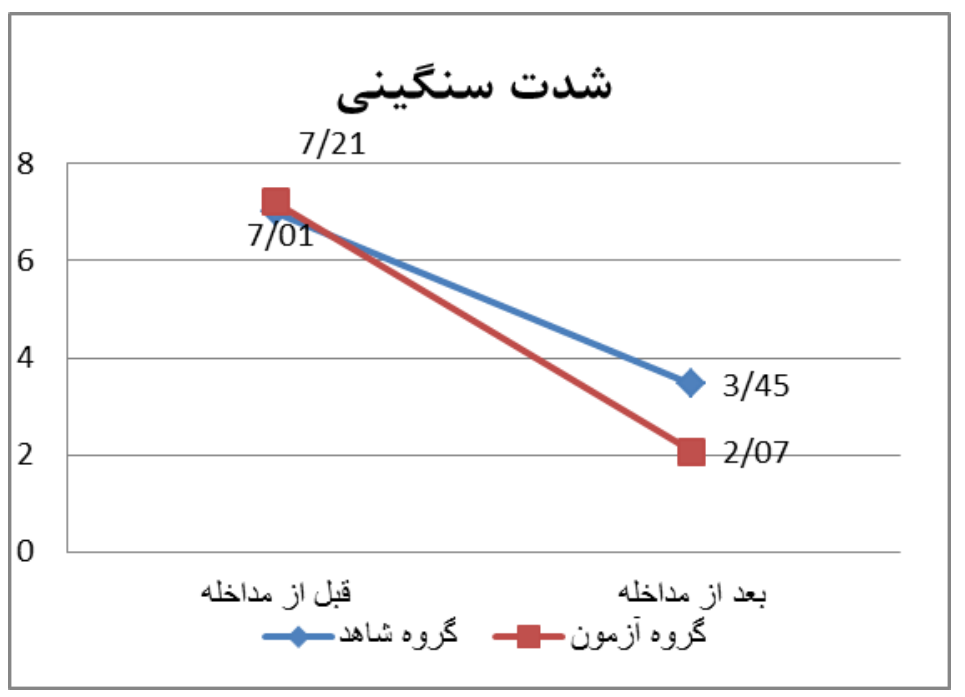

نمودار r الف: تغييرات ميانكَين شدت سنكَينى در كروه آزمون وشاهد قبل و بعد از مداخله

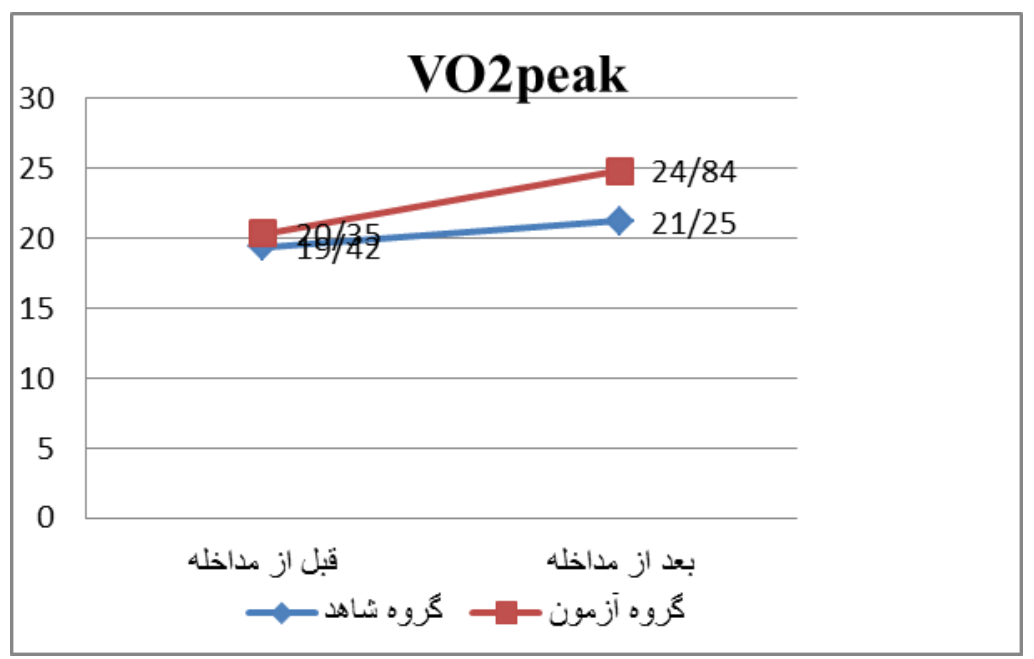

نمودارr ب : تغييرات ميانكين VO2 در تروه آزمون وشاهد قبل و بعد از مداخله

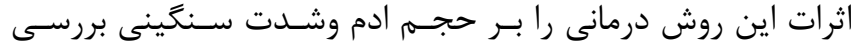

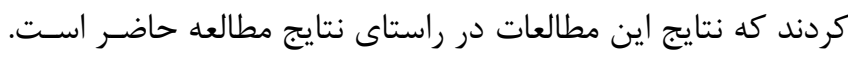

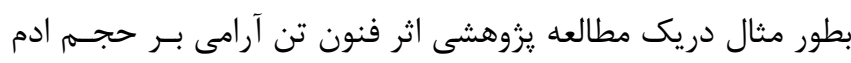

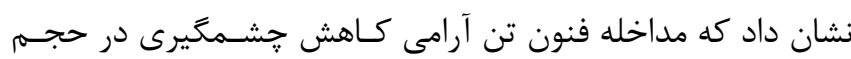

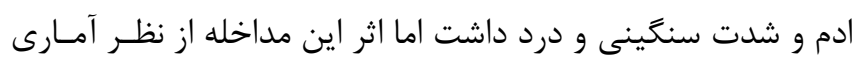

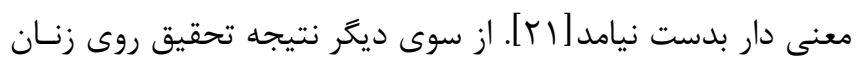

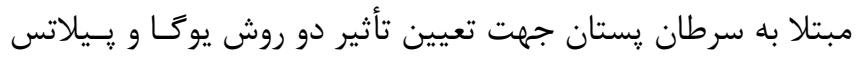

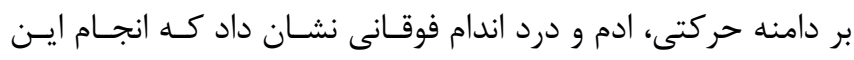

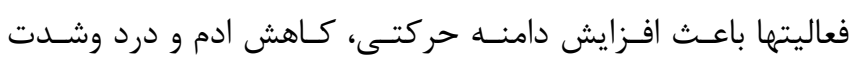

\section{بحث و نتيجه گيرى}

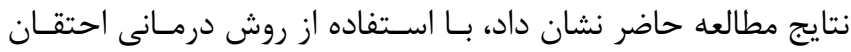

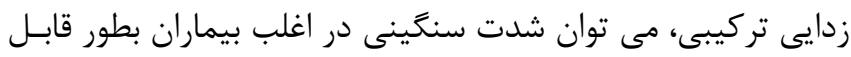

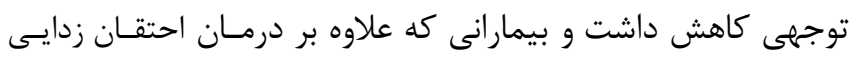

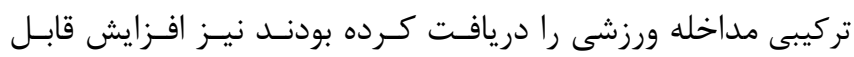

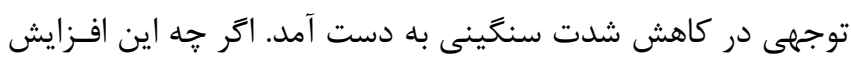

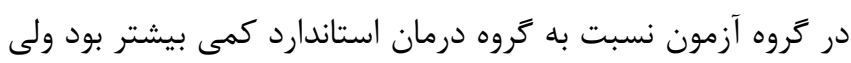

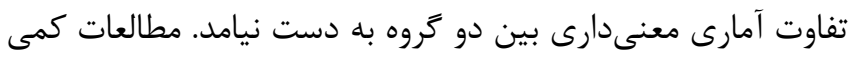

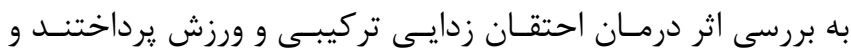


مديترانه اي، عملكرد انـدوتليال عروقى وآمـادگى قلبـى تنفسىى را

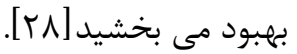

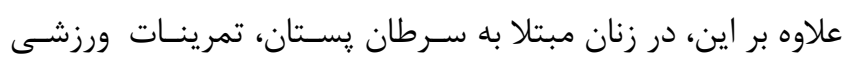

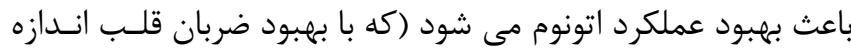

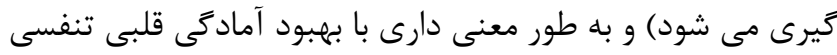

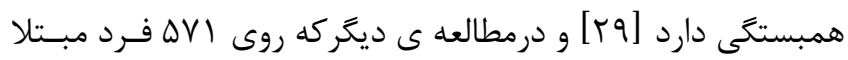

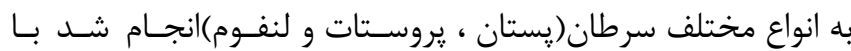
استفاده از يك برنامه تمرينى تحت نظارت با تجويز سه بار در هفتهانها

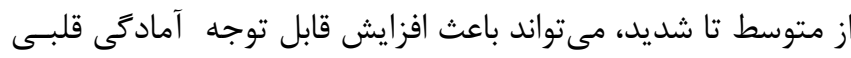

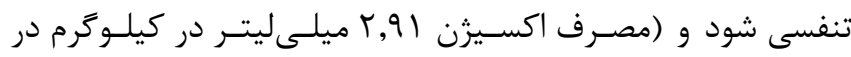

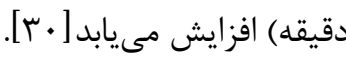
سازوكارهاى افزايش آمادَى قلبى تنفسى طور دقيق شناخته نشـده

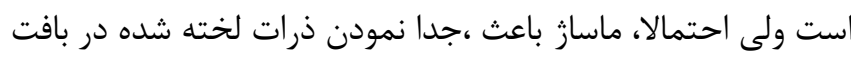

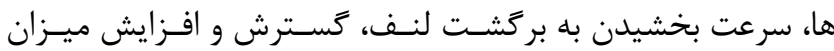

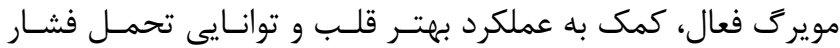

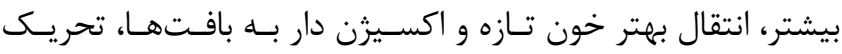

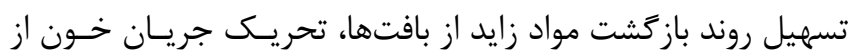

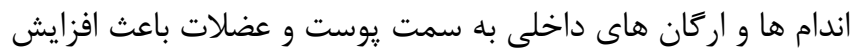

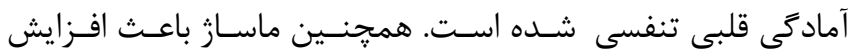
خاصيت ارتجاعى عضلات و مفاصل مىشود و مقدار اكسيزن عضلات

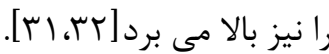

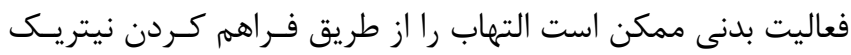

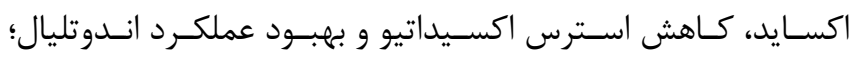
تسكين دهد [بس]. همجنين اين احتمال وجود دارد كه اثرات آنتى اكسيدانى فعاليت ورزش بتواند باعث كاهش التهاب، ادم ودر نتيجـهـ

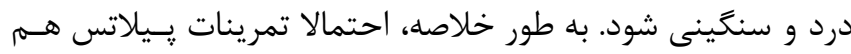
به طور مستقيم از طريق كاهش توليد سايتوكينها در بافت خربسي،

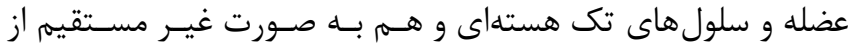

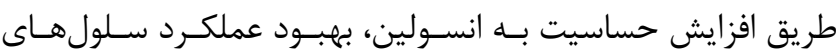

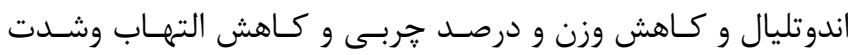

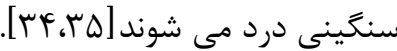

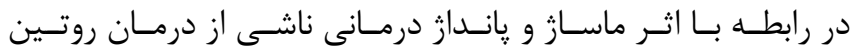

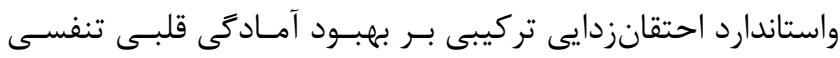
يزوهش مستقيمى يافت نشد. در عين حال يافته هاى ديكر محققسان

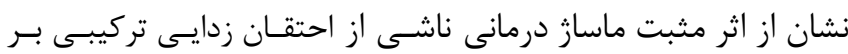
شاخصهاى بيوشيميايى ديخرى مانند كورتيزول، سروتونين، كلـوكز

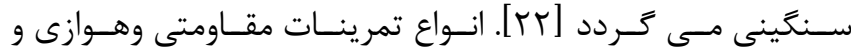
همجنين تمرينات درمانى تر كيبى متشكل از فيزيوترايى و يا حركت

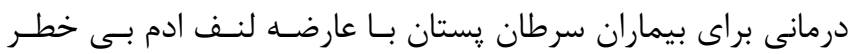

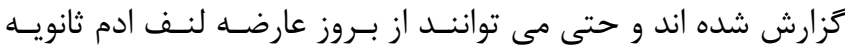

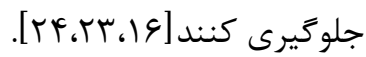

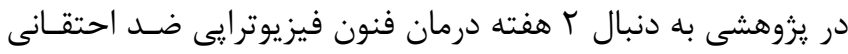

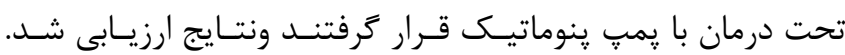

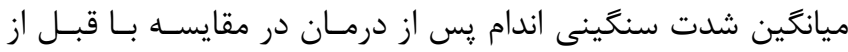

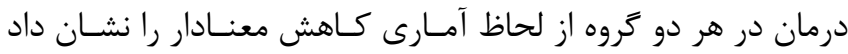

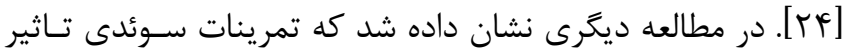
معنادار بر كاهش ميزان دامنه حركتى شانه، كيفيت زندكى و درد و دئن

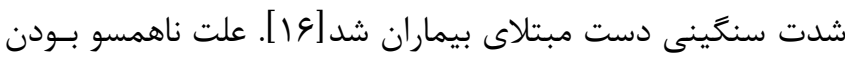

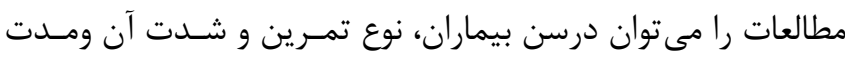

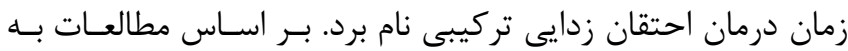

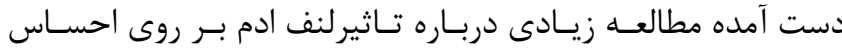

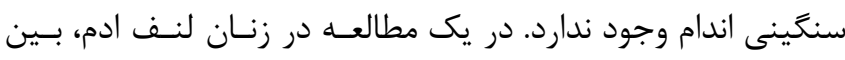
كاهش حجم لنف ادم و شدت سنكَينى اندام دركير ارتبـاط معنـادار

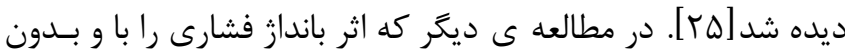

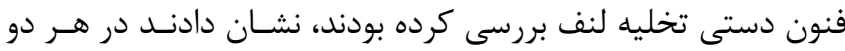

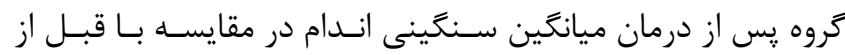
درمان به شكل قابل توجهى كاهش يافت [عب].

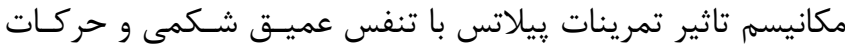

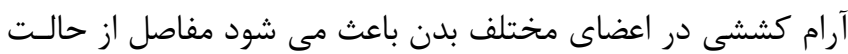

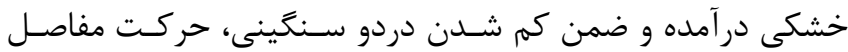

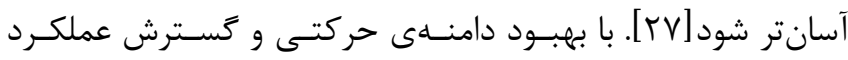

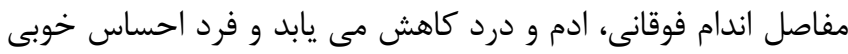

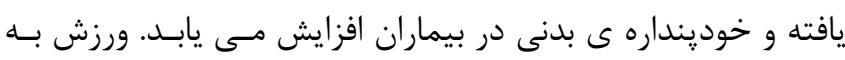

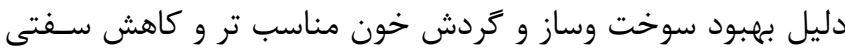

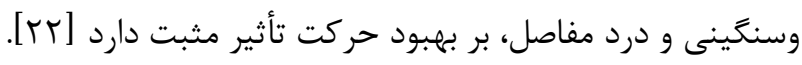
كاهش آمادگى قلبى تنفسى (Voak

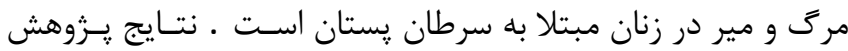

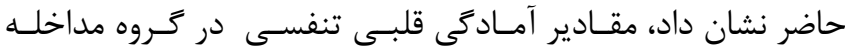

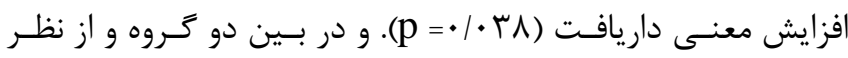

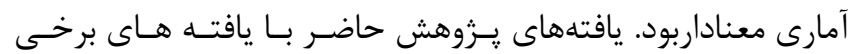
محققان همسو است. در بيماران مبتلا به سرطان يستان اسـتفاده از

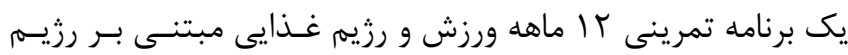


علايم لنف ادما شامل كاهش شدت سنَينى وافزايش آمادگى قلبـى

تنفسى مشاهد شـــ. بنـابراين ورزش يــيلاتس مـى توانـد بــه عنــوان

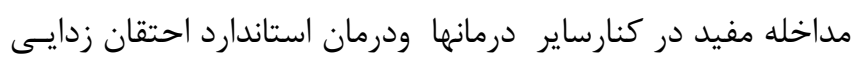
تركيبى براى بيماران مبتلا به لنف ادما در نظر گرفته شود.

\section{سمم نويسند}

رقيه مختارى حصارى: ارائه ايده، نَـارش مقالـه، تحليـل داده هـا و تفسير نتايج رقيه يوزش جديدى همكارى در نگارش مقاله، تفسير نتايج

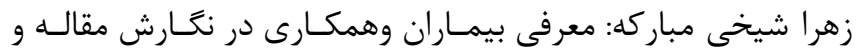
تفسير نتايج كريم ازالى: همكارى در نغارش مقاله و تفسير

\section{تشكر و قدردانى}

نويسندكان اين مقاله بر خود لازم مى دانـد تا ازتمـامى افـرادى كـهـ

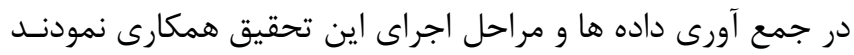

$$
\text { تشكر و قدردانى نمايند. }
$$

\section{منابع}

1. Mosadeghrad AM. Essentials of healthcare organization and management $.1^{\text {st }}$ Edition, Tehran: Dibagran; 2015

2. Mosadeghrad AM. Comments on Iran hospital accreditation System.Iranian Journal of Public Health 2016; 45: 837-842

3. Hema N, Viswanathan, BPharm, MS(CAND); andJ. Warren Salmon, PhD. Accrediting Organizations and Quality ImProvement. The American Journal of Managed Care 2000; 6: 1117-1130

4. Donahua $\mathrm{K}$, Van $\mathrm{O}$, Joint Commission international accreditation: RelationshiP to four models of evaluation. International Journal for Quality in Healthcare 2000; 12: 243-246

5. Emami Razavi H, Mohaghegh M. A Look at hospital Accreditation Standards Ministry of Health\& Medical Education. $1^{\text {st }}$ Edition, Tehran: seda; 2008 [In Pesian]

6. Mosadeghrad AM. Iran hospital accreditation: Future directions . $1^{\text {st }}$ Edition in J. Braithwaite, et al., (Eds.) Health Care Systems: Future Predictions for Global Care, Taylor \& Francis 2018: 285-291

7. Phua J, Koh Y, Du B, Tang YQ, Divatia JV, Tan CC, et al. Management of severesepsis in patients
و سايتوكاين هاى التهابى (اينترلوكين و و فاكتور نكروز دهنده آلفـا)

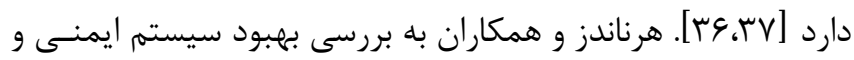

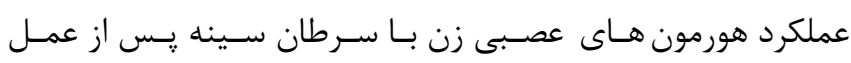

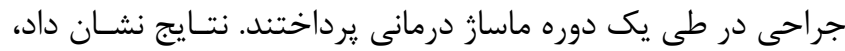
ماساز باعث كاهش كورتيزول و افزايش دويامين، سروتونين و تعـداد

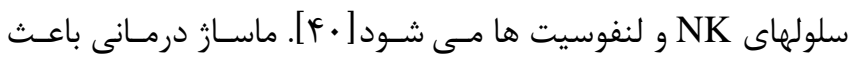

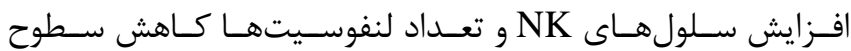
كورتيزول، كاهش نوتروفيل، كاهش سطوح انسولين و كلوكز بعـد از

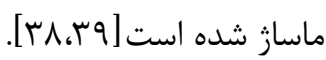
ماساز درمانى ناشى از احتقان زدايى تركيبى با كاهش اسـترس كـهـ

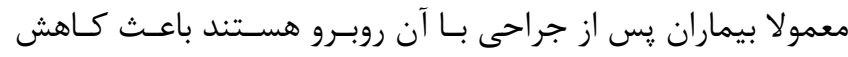
التهاب شده و ممكن است با تحريك گيرندههاى فشار و تحت تـاثير

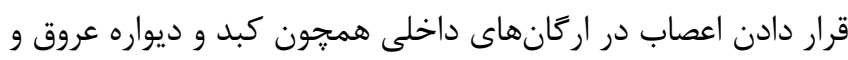
سيستم ليمبيك باعث كاهش فعاليت سـمياتيك و افـزايش فعاليـت

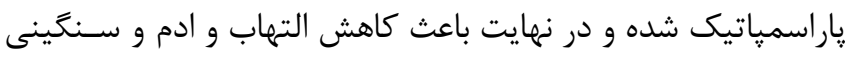

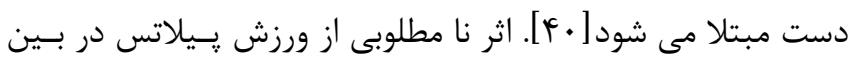
شركت كنند

admitted to Asian intensive care units: prospective cohortstudy. BMJ 2011;342:d3245

8. Alkhenizan A, Shaw C. The attitude of health care professionals towardsaccreditation: a systematic review of the literature. Journal of Family Community Medcine 2012; 19:74

9. Alkhenizan A, Shaw C. Impact of accreditation on the quality of healthcare services: a systematic review of the literature. Annals of Saudi Medicine 2011; 31: 407-416

10. Gokenbach V, Drenkard K. The outcomes of magnet environments andnursing staff engagement: a case study. Nursing Clinic of North America 2011;46: 89-105

11. Sekimoto M, Imanaka $Y$, Kobayashi H,et al. Impact of hospital accredi-tation on infection control programs in teaching hospitals in Japan. American Journal of Infection Control 2008;36:212-9

12. Lutfiyya MN, Sikka A, Mehta S,et al. Comparison of US accreditedand non-accredited rural critical access hospitals.International Journal for Quality in Health Care 2009; 21:112-8

13. Lichtman JH, Allen NB, Wang Y,et al. Stroke patient outcomesin US hospitals before the start of the 
Joint Commission Pri-mary Stroke Center certification program. Stroke 2009; 40:3574-9

14. Shaw C, Groene O, Mora $\mathrm{N}$,et al. Accreditation and ISO certification: dothey explain differences in quality management in European hospitals? International Journal for Quality in Health Care 2010;22:445-51

15. Kim YS, Jung SE, Choi BG,et al. Image quality improvement after imple-mentation of a CT accreditation program.Korean Journal of Radiology 2010;11:553-9

16. Devkaran S, O'Farrell PN. The impact of hospital accreditation on clini-cal documentation compliance: a life cycle explanation using interruptedtime series analysis. BMJ 2014;4:e005240

17. Shaw CD, Groene O, Botje D,et al. The effect of certification andaccreditation on quality management in 4 clinical services in 73European hospitals. International Journal for Quality in Health Care 2014;26:100-7

18. Chen J, Rathore SS, Radford MJ,et al. JCAHO accreditation and qual-ity of care for acute myocardial infarction.Health Affair 2003;22:243-54

19. Lutfiyya MN, Sikka A, Mehta S,et al. Comparison of US accreditedand non-accredited rural critical access hospitals. . International Journal for Quality in Health Care 2009;21:112-8

20. Lichtman JH, Allen NB, Wang Y,et al. Stroke patient outcomesin US hospitals before the start of the Joint Commission Pri-mary Stroke Center certification program.Stroke2009;40:3574-9

21. Schmaltz SP, Williams SC, Chassin MR,et al. Hospital performance trendson national quality measures and the association with Joint Commissionaccreditation. Journal of Hospital Medcine 2011;6:454-61

22. Song $\mathrm{P}, \mathrm{Li} \mathrm{W}$, Zhou Q. An outpatient antibacterial stewardship inter-vention during the journey to JCI accreditation. BMC Pharmacology and Toxicology 2014; 15:8.10

23. Halasa YA, Zeng W, Chappy E,et al. Value and impact of internationalhospital accreditation: a case study from Jordan.Eastern Mediterrian Health Journal 2015;21:90-9

24. Nomura ATG, Silva MB, Almeida MA. Quality of nursing documentationbefore and after the Hospital Accreditation in a university hospital. RevLat Am Enferm 2016;24:e2813

25. Yıldız MS, Öztürk Z, Topal M,et al. Effect of accreditation and certifica-tion on the quality management system: analysis based on Turkish hospitals.International Journal of Health Planning and Management 2019;34:e1675-87

26. Hadley TR, McGurrin MC. Accreditation, certification, and thequality of care in state hospitals. Psychiatric Services1988;39:707-10

27. Schmaltz SP, Williams SC, Chassin MR,et al. Hospital performance trendson national quality measures and the association with Joint Commissionaccreditation.Journal of Hospital Medcine 2011;6:454-61

28. Aboshaiqah AE, Alonazi WB, Patalagsa JG. Patients' assessment ofquality of care in public tertiary hospitals with and without accredita-tion: comparative cross-sectional study.Journal of Advanced Nursing 2016;72:2750-61

29. Mosadeghrad A M, Akbari-sari A, Yousefinezhadi T. Evaluation of hospital accreditation standards. Razi Journal of Medical Sciences 2017; 23: 43-54 [In Pesian]

30. Iran Health Ministry, Implementation guideline of the $4^{\text {th }}$ hospital accreditation survey. Ministry of Health . Available at: http://treatment.sbmu.ac.ir/uploads/etebarbakhshi_stan dard_book_98.pdf 2019 [In Pesian]

31. Reisi N, Raeissi P, Sokhanvar M, Kakemam E. The impact of accreditation on nurses' perceptions of quality of care in Iran and its barriers and facilitators. The International journal of Health Planning and Management 2019; 34: 230-40

32. Moradi R, Nemati A, Bahmanziari N, Shokri A, Mohammadi M. The impact of accreditation on services of Isfahan University hospitals. Health Care Management Journal 2015; 6: 67-76

33. Mosadeghrad A M, Ghazanfari F. Iran hospital accreditation governance: Challenges and solutions. Payavard 2020; 14:311-332 [In Pesian]

34. Ghazanfari F, Mosadeghrad A M, Jaafari Pooyan E, Mobaraki H. Iran Hospital Accreditation Standard: challenges and solution. International Journal of Health Planning and Management 2021; 36: $1-18$

35. Pourreza A, Mosadeghrad AM, Zoleikani P. The impact of accreditation on the performance of hospital emergency departments. Journal of Health Based Research 2017; 3: 277-95

36. Jaafaripooyan E, Sharifi T, Yekani Nejad MS, Esmaeili S. Relationship between Accreditation Rank and Technical Efficiency of Hospitals Affiliated to 
Tehran University of Medical Sciences. Journal of Hospital 2018; 17: 49-57 [In Pesian]

37. Fotuhi MA, Khoshgoftar A, Bakhshande A, Karami Q, Rasti M. Evaluation of Viewpoint of Executive Management Team of Hospitals of Qom Province in Terms of the Third Generation of Hospital Accreditation Standards. Qom University Medical Sciences Journal 2018;12: 62-70 [In Pesian]

38. Yarmohammadian M, Shokri A, Bahmanziari N, Kordi K. The blind spots on Accreditation program. Journal of Health System Research 2013; 9: 1158-66

39. Mohebbifar R, Rafiei S, Asl AM, Ranjbar M, Khodayvandi M. Association between hospital accreditation and patient satisfaction: a survey in the western province of Iran. Bangladesh Journal of Medical Science 2017; 16: 77-84. [In Pesian]

40. Yousefinezhadi T, Mosadeghrad AM, Hinchcliff R, Akbari-Sari A. Evaluation results of national hospital accreditation program in Iran: The view of hospital managers. Journal of Healthcare Quality Research 2020; 35: 12-18

41. Mosadeghrad AM, Nabizade Z. Evaluation of Iranian hospital accreditation system. Payesh 2018; 17: 617-629 [In Pesian]

42. Guba EG, Lincoln YS. Competing paradigms in qualitative research. Handbook of Qualitative Research. $1^{\text {st }}$ Edition, CA: Sage: Uk, 1994; 105-117

43. Husserl E. Phenomenology and the foundations of the sciences. Germany: Springer Science \& Business Media 2001: 108

44. Maggs-Rapport F. Combining methodological approaches in research: Ethnography and interpretive phenomenology. Journal of Advanced Nursing 2000; 31: $219-25$

45. Braun V, Clarke V. Using thematic analysis in psychology. Qualitative research in psychology. Qualitative Research in Psychology 2006; 3: 77-101

46. Mosadeghrad AM, Shakibaei E. Hospital accreditation implementation prerequisites. Journal of Hospital 2017;16: 43-56 [In Pesian]

47. Salehi $Z$, Peyrovi $H$. Challenges for the implementation of the accreditation process in hospitals: a narrative review, Nursing Care Research
Center, Iran University of Medical Sciences. Iranian Journal of Nursing 2017; 30: 23-34 [In Pesian]

48. Mahmood Nekoei-Moghadam, Mohammadreza Amiresmaili, Mohammadhosein Iranemansh, Mahla Iranmanesh. Hospital accreditation in Iran: A qualitative case study of Kerman hospitals, International Journal of Health Planning and Management 2018;33: 1-8

49. Bahrami M, Akbari M, Emami M, Falahzadeh $\mathrm{H}$. Designing an administrative structure for Iranian hospitals" accreditation based on the stakeholder's viewpoints". Journal of Shahid Sadoughi University of Medical Sciences 2016; 15: 208-223 [In Pesian]

50. Mosadeghrad, A.M. Towards a theory of quality management: an integration of strategic management, quality management and project management. International Journal of Modelling in Operations Management 2012; 2: 89-118

51. Bohigas L1, Brooks T,Donahue T, Donaldson B, Heidemann E, Shaw C,et al. A comparative analysis of surveyors from six hospital accreditation programmes and a consideration of the related management issues.International Journal for Quality in Health Care 1998;10:7-13

52. Meireles VC, Labegalini CM, Baldissera VD. Tracer Methodology and the quality of care: integrative literature review. Revista Gaucha de Enfermagem 2019;40: e20180142

53. Joint Commission International Accreditation Hospital. Survey Process Guide, $4^{\text {th }}$ Edition. Joint Commission International: USA, 2013

54. Canada accreditation, Health Care Accreditation Process. Available from: https://accreditation.ca/. Retrieved July 5, 202040

55. Australian Council on Healthcare Standards. Australian Council on Healthcare Standards International. Available at https://www.achs.org.au/Retrieved June 27, 2020

56. Introduction to DDKM. Available at :httPs://www.ikas.dk/den-danske-kvalitetsmodel/ddkm-inenglish/introduction-to-ddkm.2021 